\title{
THE SPEED OF HUMAN SPERMATOZOA AND THE EFFECT ON IT OF VARIOUS DILUENTS, WITH SOME PRELIMINARY OBSERVATIONS ON CLINICAL MATERIAL*
}

\author{
GLARE HARVEY \\ Department of Zoology, Hatherly Biological Laboratories, \\ University of Exeter
}

(Received 2 I st September 1959)

\begin{abstract}
Summary. A method is described for measuring the speed of human spermatozoa.

Dilution with seminal plasma, buffered glucose solution and normal saline cause a fall in the average velocity of spermatozoa. During incubation the speed falls more rapidly in seminal plasma than in artificial diluents.

The speed of the spermatozoa is sensitive to changes in $\mathrm{pH}$ of the suspending fluid which produce no measurable drop in motility.

Seminal plasma from other semen samples may have a stimulating or depressing effect on speed when added to semen, but in most cases produces no change.

Semen judged as satisfactory on other counts has a higher average speed, and a greater number of relatively fast spermatozoa, than semen of poorer quality.

The speed of spermatozoa in cervical mucus, and in semen, indicates that it would be possible for them to enter the Fallopian tubes by their own activity within half an hour of insemination.
\end{abstract}

\section{INTRODUCTION}

In the study of the spermatozoa of domestic animals it is possible to estimate the effect of environmental conditions by measuring changes in the rates of respiration or fructolysis (Mann, 1958) or by impedence change frequency (Dott \& Walton, 1953). Owing to the low density of spermatozoa in human semen these techniques are difficult or impossible to apply without first concentrating the sperms by centrifugation, and even so only very good samples can be used.

The determination of changes in percentage motility, though easier to assess in human semen, than in semen of greater density, is subject to considerable error of a kind not easy to assess. Direct assessment of motility is qualitative rather than quantitative, whether it is expressed as a percentage (MacLeod,

* Read at the Annual Conference, 1959, of the Society for the Study of Fertility. 
195I) or by a scale of values such as that used by Emmens (1947). Both authors indicate that the observations, if they are to be consistent and comparable, should be made by the same observer, or by two or more working in close collaboration. The method of the differential count of immobile spermatozoa with and without treatment with osmic acid on a counting slide (Harvey \& Jackson, 1945) is objective, but has a large and rather indeterminate statistical error, which necessitates counting a very large number of spermatozoa before significant differences can be established between sperm suspensions with activities of the same order.

In view of these difficulties, and also because in clinical studies it is recognized that 'quality' of movement is probably at least as important as percentage motility as a measure of the potential fertility of semen, it seemed desirable to devise a method for estimating the speed of movement of spermatozoa. It is obvious, by casual observation, that factors such as temperature and long incubation in diluting media affect the rate at which spermatozoa move, and it seemed likely that speed of movement might be susceptible to other factors.

Preliminary experiments were made with the photographic method suggested by Rothschild (1953), but this was abandoned, partly because of technical difficulties in this laboratory, and partly because of the complication of large numbers of dead and non-progressing spermatozoa in most of our ejaculates. The method of Baker, Cragle, Salisbury \& VanDemark (1957) is unsatisfactory for human semen for the same reasons, and also because it assumes that the spermatozoa are travelling in straight lines, which is by no means true of human spermatozoa in a counting chamber.

\section{METHOD}

The apparatus required consists of a microscope contained in a 'hot-box' controlled at $36^{\circ}$ to $37^{\circ} \mathrm{C}$, a dictating machine, a number of Thoma counting slides and a stop watch. In addition an incubator maintained at $36^{\circ} \mathrm{C}$ is required for warming glassware and holding the semen and sperm suspensions to be used.

In order to economize on semen, the technique has been designed for $0.05 \mathrm{ml}$ of semen for each sperm suspension, the semen being measured in an automatic micro-pipette. The suspensions are made in $2 \times \frac{3}{4}$ in. glass tubes, and the standard rate of dilution is one part semen to nine of diluent. The measured volumes of diluents, and an adequate volume of semen are warmed in the incubator for I 5 to 30 min before the experiment is started. The semen is then mixed by drawing it in and out of the pipette several times, and $0.05 \mathrm{ml}$ is transferred to the first tube of diluting fluid, with which it is mixed in the same way. A drop of this suspension is then run into the chamber of a counting slide, and the slide is immediately placed on the stage of the microscope in the 'hot-box'. One and a half minutes is allowed for equilibration, making a maximum of $2 \mathrm{~min}$ from mixing to the determination of the speed of the first spermatozoon.

The microscope is fitted with a 6-mm objective, the field of which circumscribes a grid on the counting slide with eleven small squares in each side. The central square of one side is viewed. When the suspension is made with good 
quality semen there is usually a sperm moving into the grid through this square and the first sperm to cross the base line is selected. With less active semen, each square of the grid is examined in turn until a progressing sperm is found.

As the selected sperm crosses a line of the grid the stop watch is started. As the sperm passes from square to square the direction of movement is spoken into the microphone. Text-fig. I shows how the directions are named. The track is followed for five to ten squares, and as the last line is crossed the watch is stopped. Only the starting and stopping of the watch need synchronize exactly with the sperm crossing a line. In timing rapidly moving sperms the last two or three directions are often spoken after the watch has been stopped. The time

$(a)$

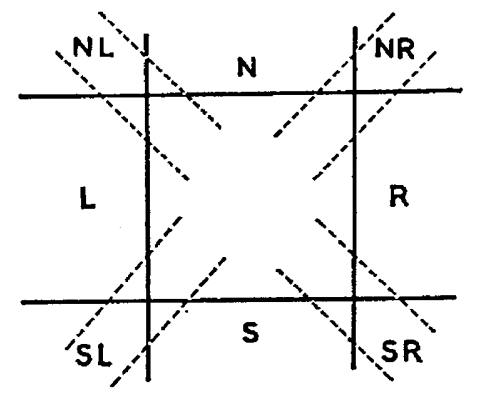

DIRECTION OF MOVEMENT OF SPERMATOZOA OVER THE GRID

(b)
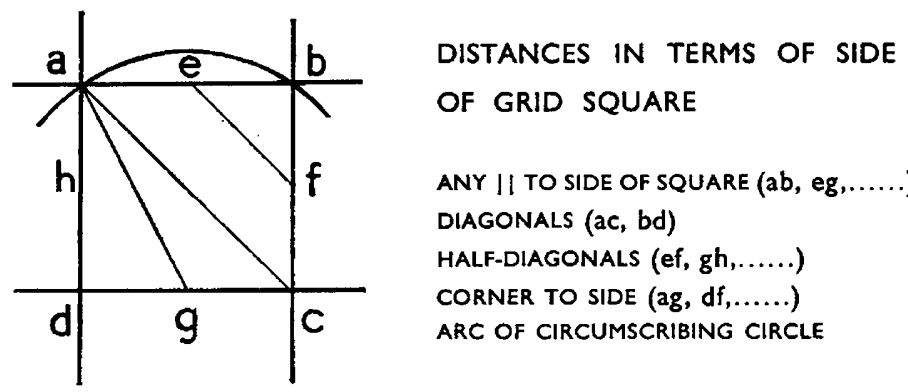

TEXT-FIG. I. (a) The method of recording the direction of progress of the spermatozoa.

(b) Approximate length of tracks across the grid square.

taken for the track, measured to the nearest half second, is spoken into the microphone. The process is repeated, each side of the grid being used in rotation for selecting a spermatozoon, until a sufficient number of tracks has been timed. It makes little difference to the average speed in a given suspension whether ten or twenty tracks are used, but differences observed in experimental work are, of course, of greater significance when based on twenty tracks. The time for recording twenty tracks varies from 3 to $5 \mathrm{~min}$, so that the observations are completed $7 \mathrm{~min}$ after mixing semen and diluent, and tests in different suspensions can follow one another at $7 \frac{1}{2}$-min intervals.

Transcribing from the tape takes rather less time than recording, as there are no pauses between the tracks. Text-fig. I shows how the data on the tape recording are interpreted into terms of distance. In earlier work the tracks were plotted on $\frac{1}{4}$ in. squared paper, the angles being rounded off, and the lines obtained were measured with calipers. This was rather time consuming, and the length 
of the track is now calculated directly from the transcribed recording as shown in Text-fig. 2. It was found that the difference between the measured and calculated distances never exceeded $5 \%$ and was usually only $\mathrm{I}$ to $2 \%$ of the track length.

The final result for each suspension is a list of ten or twenty velocities expressed as $\mu / \mathrm{sec}$. The average of these values is spoken of as the 'speed' of the sperm in the suspension. Differences between sets of observations can be assessed by any method for the analysis of variance, or by grouping the velocities and using a $\chi^{2}$ technique. The results are, however, very suitable for testing by a ranking technique, and in comparing the results reported here the MannWhitney U Test has been used (Siegel, 1956).

There are two obvious criticisms of the method of determining speeds. It has been assumed that the spermatozoa are moving in a horizontal plane, although
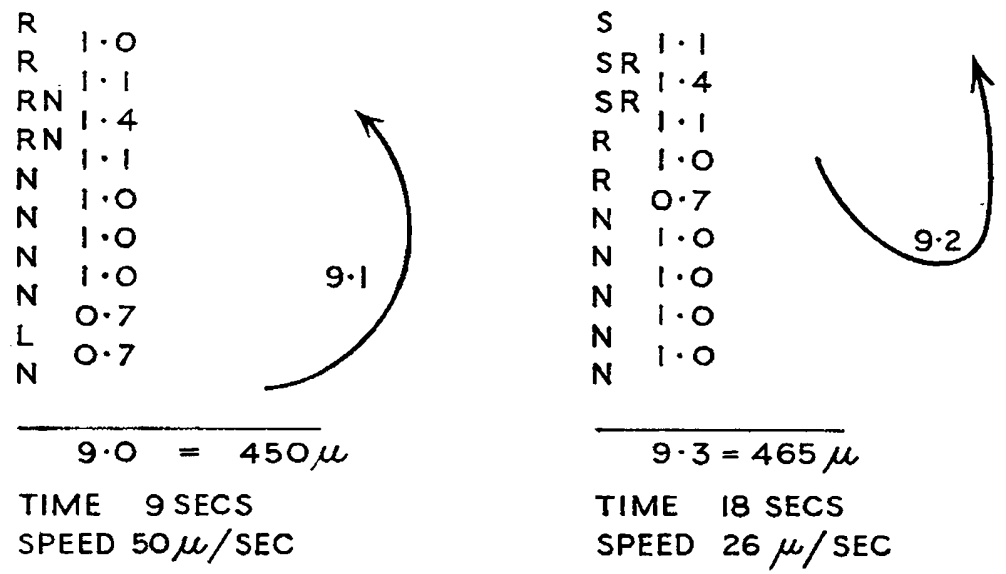

TEXT-FIG. 2. Conversion of recorded directions into distance by calculation and by measurement. The side of each square of the grid is $5^{\circ} \mu$.

the depth of fluid in the counting chamber would permit some vertical movement. However, the sperms cannot of course be followed if they move out of focus, as the position of the objective is not altered during the observations, and in practice the head and tail are clearly defined during the timing, and the focal depth of the objective is small compared with the length of the track.

The second criticism is that selection of sperms is not truly random. As the sperms are distributed in a volume of fluid which is large compared with their size, and are moving in all directions, one would expect that the likelihood of a sperm moving with a given speed being found in a particular square at a particular moment would be related to the frequency with which sperms of such speed occurred in the population, and the error introduced by the selection of definite squares should introduce only such errors as are inherent in most grid techniques. In order to discover if any obvious bias existed towards the selection of faster or slower spermatozoa, five sets of twenty tracks each were timed on drops taken from the same suspension of an active semen sample, the time from starting the first set to completing the fifth being $25 \mathrm{~min}$. Text-fig. 3 shows the 
frequency distribution of sperms of different speeds in the sample of one hundred, and it will be seen that there is no obvious bias.

\section{DILUTION}

In most cases sperm speeds can be determined only in dilutions of semen, as in the undiluted semen the sperms obscure the lines of the grid, and it is very difficult in a dense population to keep one's eye on a particular spermatozoon. The diluents most frequently used were $0.9 \%$ sodium-chloride solution ('normal

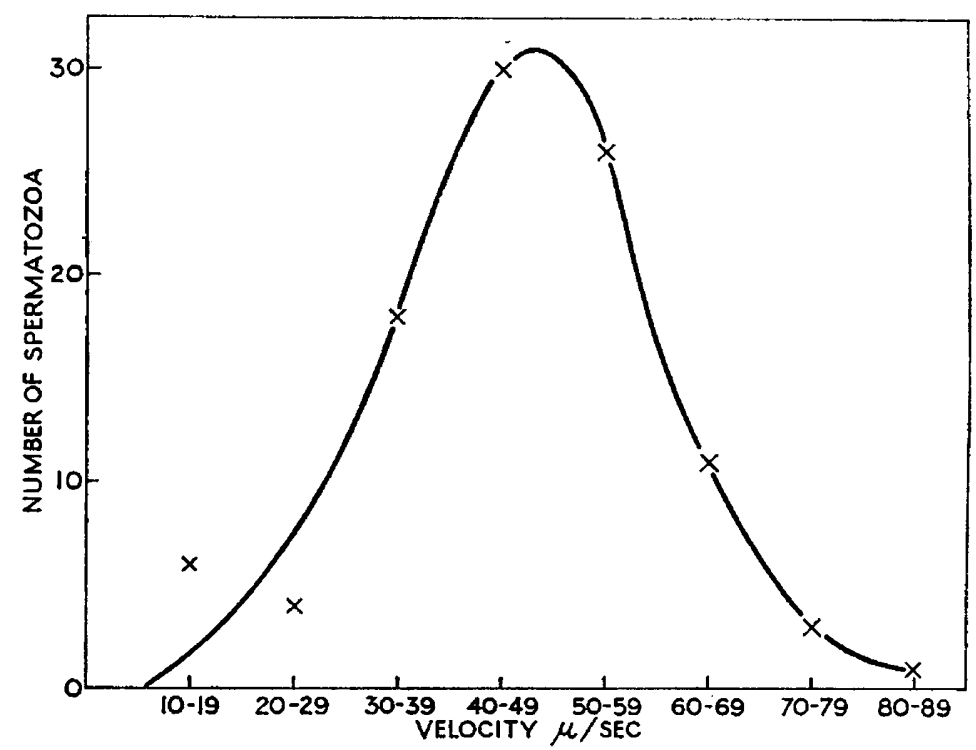

TExT-FIG. 3. The frequency distribution of the speed of one hundred sperms from a single dilution of human semen.

saline'), and glucose-phosphate solution, and it was necessary to know what effect, if any, these fluids had on the speed of the sperms. Comparisons were first made with semen diluted with its own seminal plasma from which the sperms had been removed by centrifugation. Dr T. Mann suggested that even diluting with plasma might alter the sperm speed, so a series of experiments was carried out to check this point.

It is possible to determine the speed of sperms in undiluted semen when the sperm density does not exceed 50 million/ml. Unfortunately samples with densities in this range frequently have a low percentage motility, and when they are diluted the number of active sperms in the microscope field is insufficient for efficient speed determination. Nine semen samples have been received with a low density, but with adequate numbers of progressing sperms.

\section{RESULTS}

Text-fig. 4 summarizes the results of observations on these nine samples. The initial average speed in undiluted semen varied from $68 \mu / \mathrm{sec}$ to $30 \mu / \mathrm{sec}$, and in order that the results could be combined, all the speeds for dilutions of each 
sample have been expressed as a percentage of the initial speed of that sample in the undiluted semen. After the semen and diluents had been warmed to $36^{\circ} \mathrm{C}$, twenty sperm tracks were timed in the undiluted semen; following this, at $7 \frac{1}{2}$-min intervals, dilutions were made (I part semen to 9 of diluent), and speeds determined, in sperm-free plasma, glucose-phosphate solution, and normal saline. Semen and dilutions were kept at $36^{\circ} \mathrm{C}$ and a second set of determinations of speed was made on each at $\mathrm{I} \frac{1}{2} \mathrm{hr}$ after mixing.

In eight of the nine cases, there was an immediate reduction in average speed of the order of 10 to $20 \%$ when the sperms were suspended in plasma or in normal saline. A similar reduction took place in seven of the nine cases when the semen was diluted with glucose-phosphate solution. Although the change was not in most cases statistically significant in any single experiment, the

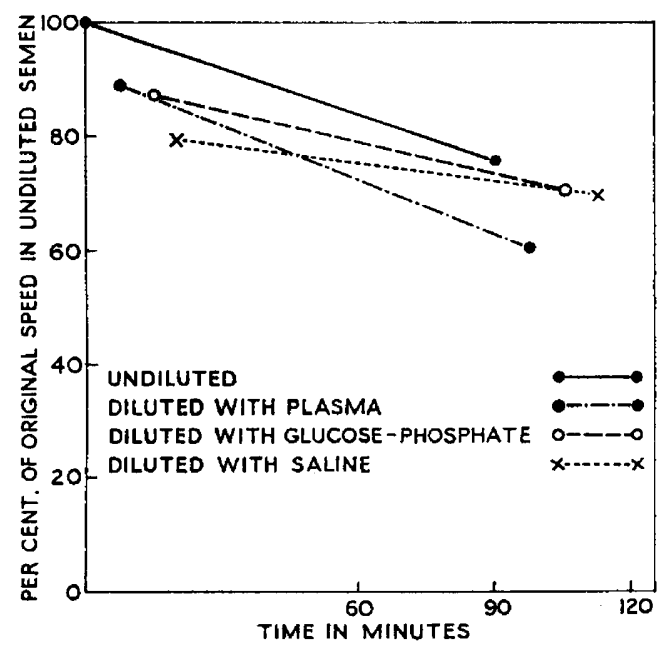

Text-Fig. 4. The effect of dilution and incubation on the velocity of sperms in nine oligospermic ejaculates.

chances of getting random variation so biased are respectively $P=0.02$ and $P=\mathrm{O} \cdot \mathrm{I}$.

After $1 \frac{1}{2} \mathrm{hr}$ incubation, the speed in all cases had fallen, and in most cases this fall was significant, but whereas all the plasma suspensions still gave speeds below those of the undiluted semen, the sperms in four of the glucose-phosphate suspensions and three of the normal-saline suspensions had average speeds slightly above those in the undiluted semen.

It would seem that dilution produces a definite fall in average speed, but that during incubation the reduction of speed with time is less in artificial diluents than in seminal plasma, whether in undiluted semen, or in semen diluted with its own plasma.

Text-fig. 5 summarizes the results of experiments carried out with ten excellent semen samples. In these cases it was not possible to determine the average speed in undiluted fluid, and the results for each sample are expressed as a percentage of the average speed immediately after mixing in a dilution in sperm-free plasma. 
The results are similar to those in Text-fig. 4 but the greater reduction in speed in seminal plasma compared with that in artificial diluents was not apparent until the suspensions had been incubated for $3 \mathrm{hr}$. This is probably

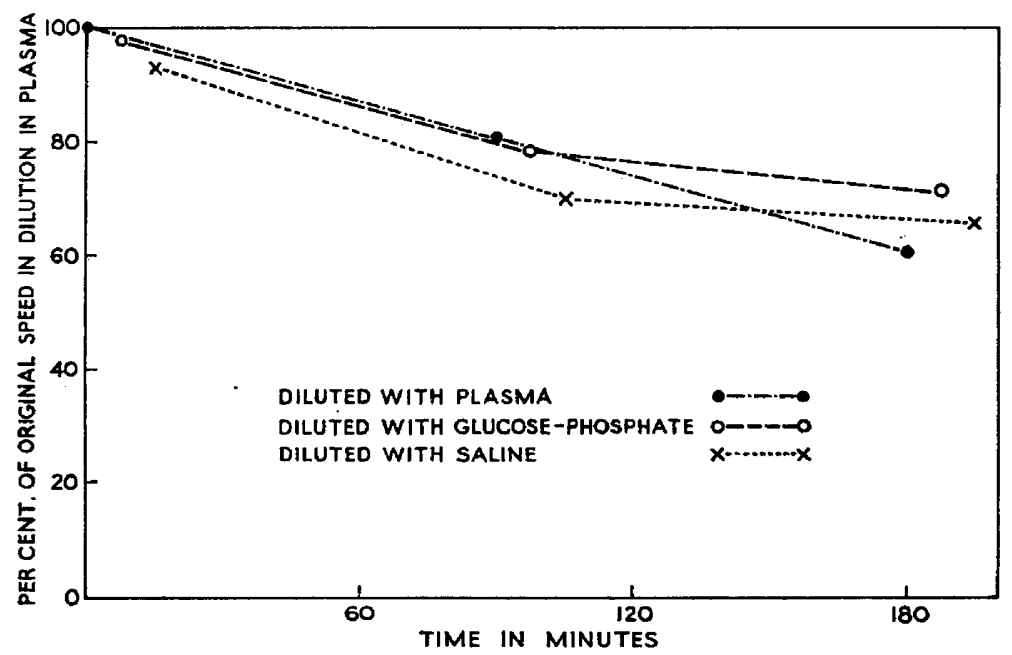

TExT-FIG. 5. The effect of dilution with own plasma and with artificial diluents on ten satisfactory ejaculates.

due to the greater resistance of spermatozoa from good quality semen to adverse factors in the environment.

VARIATION IN SPEED DUE TO SMALL CHANGES IN pH

Three experiments were carried out to test the sensitivity of sperm speeds to small alterations in the suspending medium. Sperms were suspended in glucose-

TABLE I

EFFECT OF PH OF SUSPENDING FLUID ON AVERAGE SPERM SPEED ( $\mu / \mathrm{SEC}$ ) AFTER INCUBATION

\begin{tabular}{|c|c|c|c|c|c|c|}
\hline \multirow{2}{*}{ Exp. №. } & \multirow{2}{*}{$\begin{array}{l}\text { Incubation } \\
\text { time (hr) }\end{array}$} & \multicolumn{5}{|c|}{$p H$} \\
\hline & & $6 \cdot 8$ & $7 \cdot 0$ & $7 \cdot 2$ & $7 \cdot 6$ & $8 \cdot 0$ \\
\hline $\mathbf{I}$ & $\begin{array}{l}\text { I } \\
3\end{array}$ & $\begin{array}{l}34.9 \\
19.9\end{array}$ & $\begin{array}{l}- \\
-\end{array}$ & $\begin{array}{l}39 \cdot 2 \\
36 \cdot 4\end{array}$ & $\begin{array}{l}35^{\circ} 4 \\
38 \cdot 1\end{array}$ & $\begin{array}{l}40 \cdot 4 \\
33 \cdot 0\end{array}$ \\
\hline 2 & $\begin{array}{l}\mathbf{I} \\
3\end{array}$ & $\begin{array}{l}- \\
-\end{array}$ & $\begin{array}{l}46 \cdot 2 \\
33 \cdot 5 \dagger\end{array}$ & $\begin{array}{l}- \\
-\end{array}$ & $\begin{array}{l}45^{\circ} \cdot 9 \\
44^{\cdot}\end{array}$ & - \\
\hline 3 & $\begin{array}{l}1 \\
3\end{array}$ & $\begin{array}{l}- \\
-\end{array}$ & $\begin{array}{l}43 \cdot 8 \\
28 \cdot 7 \dagger\end{array}$ & $\begin{array}{l}- \\
-\end{array}$ & $\begin{array}{l}50 \cdot 2 \\
45 \cdot 3\end{array}$ & $\begin{array}{l}- \\
-\end{array}$ \\
\hline
\end{tabular}

* Significance $P<0.01$.

$\dagger$ Significance $P<0.02>0.01$.

phosphate solutions with a $\mathrm{pH}$ range from $6 \cdot 8$ to $8 \cdot 0$. None of these solutions produced a measurable reduction in percentage motility during the course of the experiment.

Table I gives the results of these experiments, and shows that suspension in a 
slightly acid solution results in a marked fall in speed after the first hour of incubation.

DILUTION WITH PLASMA FROM SEMEN OF ANOTHER DONOR

In view of the work of Rozin (I958) on the effect of seminal plasma on the fertilizing capacity of spermatozoa, and the observations of MacLeod \& Freund (1958) of the depressing effect of some plasmas on their metabolic

TABLE 2

EFFECT OF SEMINAL PLASMa FROM OTHER DONORS ON THE AVERAGE SPEED OF SPERMATOZOA

\begin{tabular}{|c|c|c|c|c|c|c|}
\hline \multirow{2}{*}{$\begin{array}{l}\text { Exp. } \\
\mathcal{N} o .\end{array}$} & \multicolumn{2}{|c|}{$\begin{array}{c}\text { Semen } \\
\text { providing sperms }\end{array}$} & \multicolumn{2}{|c|}{$\begin{array}{c}\text { Semen } \\
\text { providing plasma }\end{array}$} & \multicolumn{2}{|c|}{$\begin{array}{l}\text { Av. speed of sperms }(\mu / \mathrm{sec}) \\
\text { after incubation for: }\end{array}$} \\
\hline & Sample $\mathcal{N} o$. & Quality & Sample No. & Quality & $2 \min$ & $90 \mathrm{~min}$ \\
\hline A & I & $\begin{array}{c}\text { Good } \\
\quad, \\
, "\end{array}$ & $\begin{array}{l}1 \\
2 \\
3\end{array}$ & $\begin{array}{l}\text { Good } \\
\text { Poor motility, } \\
\text { dense sperms } \\
\text { Poor motility, } \\
\text { few sperms }\end{array}$ & $\begin{array}{l}49 \cdot 5 \\
49^{\cdot 6} \\
45^{\cdot 6}\end{array}$ & $\begin{array}{l}30 \cdot 9 \\
3 I \cdot 2 \\
36 \cdot 4\end{array}$ \\
\hline B & 2 & $\begin{array}{c}\text { Poor motility, } \\
\text { dense sperms } \\
,\end{array}$ & 2 & $\begin{array}{l}\text { Poor motility, } \\
\text { dense sperms } \\
\text { Good }\end{array}$ & $\begin{array}{l}22 \cdot 5 \\
23 \cdot 0\end{array}$ & $\begin{array}{c}\text { insuff. active } \\
,, \quad,\end{array}$ \\
\hline C & 4 & $\begin{array}{c}\text { Very good } \\
\text {," }\end{array}$ & $\begin{array}{l}4 \\
5\end{array}$ & $\begin{array}{l}\text { Very good } \\
\text { Poor motility, } \\
\text { few sperms }\end{array}$ & $\begin{array}{l}56 \cdot 2^{*} \\
45 \cdot 3\end{array}$ & $\begin{array}{l}49^{\circ} 4^{*} \\
4^{0 \cdot 0}\end{array}$ \\
\hline D & $\begin{array}{l}6 \\
, \%\end{array}$ & $\begin{array}{c}\text { Good } \\
, "\end{array}$ & $\begin{array}{l}6 \\
7\end{array}$ & $\begin{array}{l}\text { Good } \\
\text { Poor motility, } \\
\text { few sperms }\end{array}$ & $\begin{array}{l}52 \cdot 5 \\
4^{8 \cdot 3}\end{array}$ & $\begin{array}{l}40 \cdot 5 \dagger \\
30 \cdot 4\end{array}$ \\
\hline $\mathbf{E}$ & $\begin{array}{l}8 \\
, 2\end{array}$ & $\begin{array}{c}\text { Very good } \\
, "\end{array}$ & $\begin{array}{l}8 \\
9\end{array}$ & $\begin{array}{l}\text { Very good } \\
\text { Poor motility, } \\
\text { few sperms }\end{array}$ & $\begin{array}{l}63 \cdot 5 \\
66 \cdot 5\end{array}$ & $\begin{array}{l}53 \cdot 5 \\
56 \cdot 6\end{array}$ \\
\hline $\mathbf{F}$ & $\begin{array}{l}\text { I0 } \\
,\end{array}$ & $\begin{array}{c}\text { Very good } \\
, "\end{array}$ & $\begin{array}{l}\text { IO } \\
\text { 11 }\end{array}$ & $\begin{array}{l}\text { Very good } \\
\text { Azoospermic }\end{array}$ & $\begin{array}{l}56 \cdot 5 \\
60 \cdot 6\end{array}$ & $\begin{array}{l}49 \cdot 9 \\
50^{\circ} \cdot 9\end{array}$ \\
\hline G & $\begin{array}{l}12 \\
13 \\
13 \\
" y\end{array}$ & $\begin{array}{l}\text { Good } \\
\text { Good } \\
\text {," }\end{array}$ & $\begin{array}{l}12 \\
13 \\
13 \\
12\end{array}$ & $\begin{array}{l}\text { Good } \\
\text { Good } \\
\text { Good } \\
\text { Good }\end{array}$ & $\begin{array}{l}46 \cdot 3^{*} \\
38 \cdot 0 \\
33 \cdot 9^{*} \\
53 \cdot 0\end{array}$ & $\begin{array}{l}- \\
- \\
- \\
-\end{array}$ \\
\hline
\end{tabular}

* Significant.

$\dagger$ Not significant, difference due to one excessively fast spermatozoon.

activity, it was of interest to find if the speed of spermatozoa when diluted with their own seminal plasma differed from that when diluted with plasma obtained from another sample of semen. The results of these experiments are shown in Table 2.

In experiments $\mathrm{A}, \mathrm{C}, \mathrm{D}$ and $\mathrm{E}$, sperms from active semen were suspended in seminal plasma obtained by centrifuging semen of poor percentage motility. In only one case did the plasma exert a depressing effect on the sperm speed.

In experiment $B$, plasma from an active specimen was used with sperms from a dense but poorly motile semen. No stimulation was observed. 
The spermatozoa used in experiment $\mathrm{F}$ were from a seminal specimen with a sperm density of $470 \mathrm{million} / \mathrm{ml}$ and a motility of $40 \%$ when received, $3 \frac{1}{2} \mathrm{hr}$ after ejaculation. The plasma used for dilution was from an azoospermic ejaculate. It was thought that there might be stimulating substances in seminal plasma which could become depleted by the metabolism of so many active spermatozoa, and which could be replenished from the azoospermic plasma. However, no significant increase in speed was observed.

Experiment $G$ was the only one in which there was evidence of a stimulating substance. Both the semen samples were excellent by the usual tests, but the spermatozoa in Sample I 3 appeared to move rather slowly for so good a sample. Plasma from Sample I 2 had an immediate stimulating effect on the sperm from Sample 13, while plasma from Sample I3 reduced the speed of the sperm in Sample I2. Unfortunately it was not possible to make later observations on these suspensions. There was no detectable difference in viscosity between the plasma samples.

Of the nine plasmas tested, two depressed and one increased the speed of spermatozoa from other semen. The remainder produced no detectable effect. It follows that though the plasma may affect the rate of sperm movement, it is by no means the only factor involved, or alternatively, most spermatozoa may be insensitive to the effective components in the plasma.

\section{THE RELATION OF SPERM SPEED TO POTENTIAL FERTILITY}

A large number of speed determinations have been made on sperms from the semen of husbands of patients attending the sub-fertility clinic. For routine determination of the density and percentage motility of the spermatozoa, semen is diluted with glucose-phosphate buffer $(\mathrm{pH} 7 \cdot 6)$ and incubated at $36^{\circ} \mathrm{C}$. The speed of the sperms was determined during the second hour of incubation. Preliminary experiments showed that the velocity of sperms so incubated was not significantly affected by the age of the semen provided it was incubated not less than 2 or more than $5 \mathrm{hr}$ after ejaculation. Some of the routine dilutions were made at the rate of I part of semen to 19 of diluent, but speed in this dilution did not differ from that in the routine I part semen to 9 of diluent. The averages are usually based on only ten tracks.

The slowest individual sperm timed moved at $2 \mu / \mathrm{sec}$. Such sperms hardly appear to be progressing. The fastest speed in this series was $95 \mu / \mathrm{sec}$, but speeds of I Io $\mu / \mathrm{sec}$ have been recorded. At this speed the sperms become rather difficult to follow. The lowest average speed observed was $19.5 \mu / \mathrm{sec}$ and the highest $63.5 \mu / \mathrm{sec}$.

Text-fig. 6 shows the distribution of average speeds in semen samples from donors of varying fertility indices (Harvey, 1953). Men with a fertility index of $5^{\circ}$ or over are regarded as of adequate fertility, those with an index between $3^{\circ}$ and 49 are somewhat below normal, while those with a fertility index below 30 are definitely sub-fertile, though by no means always incapable of producing fertilization. The samples in this last group represent only the more fertile of these sub-fertile men, as a minimum of 2 million active sperms per $\mathrm{ml}$ of semen is required for speed determination. 
It is obvious from the figure that in the more fertile samples the average speed tends to be higher than in those of lower potential fertility, and this difference is highly significant $(P<0.01)$.

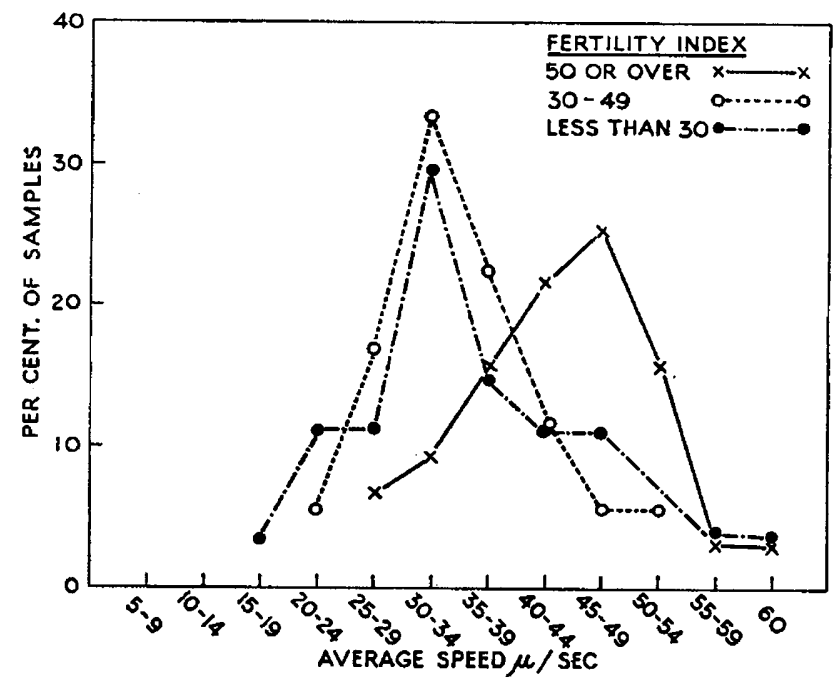

Text-Fig. 6. Proportion of samples with different average speeds in dilutions of semen of good, medium and poor quality.

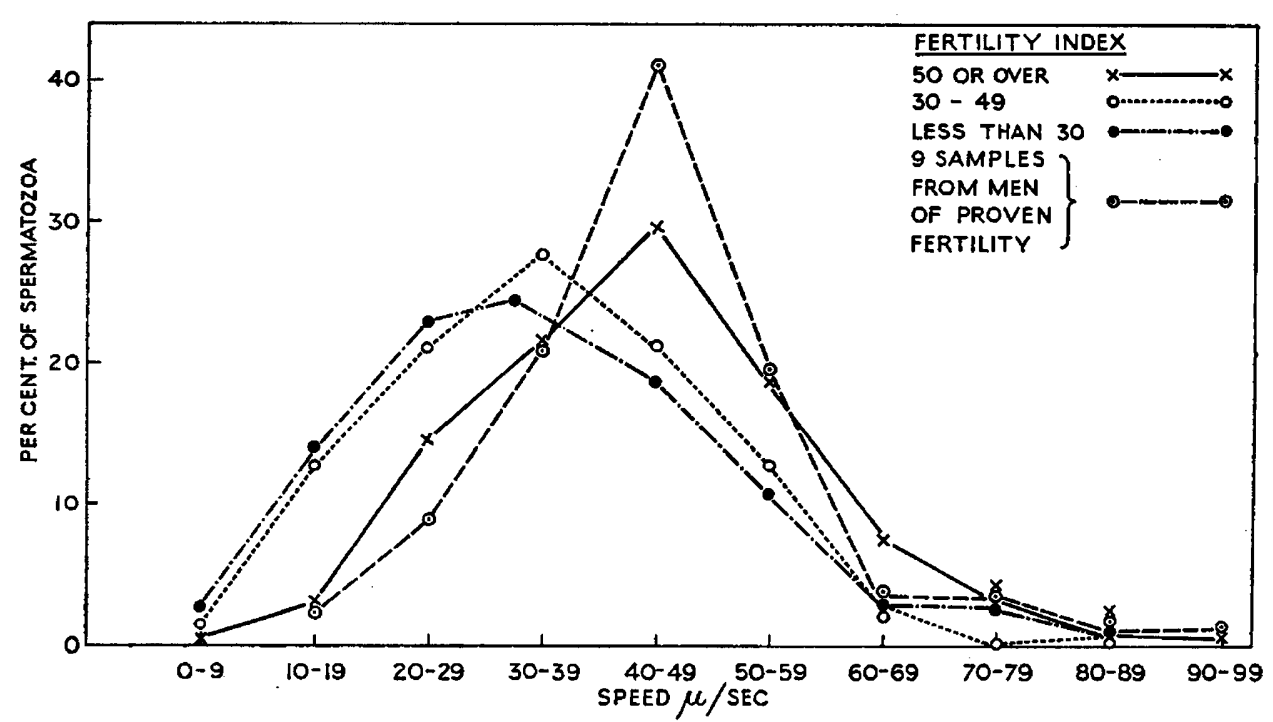

Text-FIG. 7. Proportion of sperms with different speeds in semen of good, medium and poor quality, and in semen from men of proven fertility.

Text-fig. 7 shows the distribution of sperms of different individual speeds in the same three groups of donors. It will be seen that there are a few very fast sperms in all three groups, but the significant difference lies in the speed of the 
modal group, and in the proportion of the total number of sperms with a speed over $40 \mu / \mathrm{sec}$.

Superimposed on Text-fig. 7 is a graph of the distribution of sperm speeds in nine samples of semen from nine men whose wives were not patients at the subfertility clinic, and who had several young children. These semen samples did not have exceptionally high fertility indices, in fact six of them were marginal for this group, the index being between $5^{\circ}$ and 60 . It will be seen from the figure that although the peak group is the same as in the cases from the clinic with fertility indices over $5^{\circ}$, the proportion of the total number of sperms which have speeds between 40 and $50 \mu / \mathrm{sec}$ is appreciably greater, and in spite of the small number of cases in the group with proven fertility this difference is probably significant $(P<0.05>0.02)$.

This observation suggests that perhaps the speed of the spermatozoa may be a factor in differentiating between the fertility of semen samples which on the basis of density, motility and sperm morphology appear very similar. However, this is not supported by evidence from two donors in the lowest fertility index group whose wives have recently become pregnant. The sperm of the first donor, under the conditions of the experiment, had an average speed of $36 \cdot 4$ $\mu / \mathrm{sec}$, and $40 \%$ of the sperms had speeds above $40 \mu / \mathrm{sec}$, which was good for this group. The semen from the second donor, however, gave an average sperm speed of $19.8 \mu / \mathrm{sec}$, and none of the sperms observed were moving as fast as $40 \mathrm{\mu} / \mathrm{sec}$. Much more information is required before the clinical usefulness of determining sperm speeds can be assessed.

\section{SPEED IN FRESH SEMEN}

As already stated the routine examinations have been made on spermatozoa which had spent two or more hours in seminal plasma at room temperature before dilution. In two cases the change in the speed has been followed from dilutions made first at $45 \mathrm{~min}$ after ejaculation, and then at hourly intervals for several hours. In these cases the initial dilution gave average speeds $20 \%$ higher than

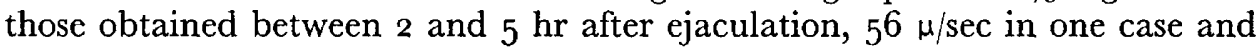
$63 \mathrm{~m} / \mathrm{sec}$ in the other, with more than half the sperms moving at speeds of more than $60 \mu / \mathrm{sec}$. It seems likely that sperms which are in the first fraction of the ejaculate at the time of emission will be moving at least another $20 \%$ faster than they would be $45 \mathrm{~min}$ later after coagulation and liquefaction. Allowing also for the depression of speed on dilution already reported, it is probable that in fertile semen the average speed of freshly ejaculated sperms in the first fraction of the plasma is in the region of $75 \mu / \mathrm{sec}$ and that many of the sperms will be moving at over roo $\mu / \mathrm{sec}$, and in this respect compare not unfavourably with bull sperms (Rothschild, I953).

\section{SPEED IN CERVICAL MUCUS}

The speed of spermatozoa in cervical mucus has been determined in three cases. Two of these were in post-coital mucus, the other in mucus used for an invasion test (Harvey, I954). 
I. Post-coital mucus obtained $40 \mathrm{hr}$ after intercourse. Average speed I9.3 $\mu / \mathrm{sec}$. Maximum speed $32 \mu / \mathrm{sec}$.

2. Post-coital mucus obtained $18 \mathrm{hr}$ after intercourse. Average speed $26 \cdot 6$ $\mu / \mathrm{sec}$. Maximum speed $37 \mu / \mathrm{sec}$.

3. Invasion test. Average speed in mucus after $\mathrm{I} \mathrm{hr}$ incubation $27 \cdot \mathrm{I} \mu / \mathrm{sec}$. Maximum speed $59 \mu / \mathrm{sec}$. Average speed in semen used for the test when diluted with glucose-phosphate solution $48 \cdot 2 \mu / \mathrm{sec}$. Maximum speed $60 \mu / \mathrm{sec}$.

A speed of $27 \mu / \mathrm{sec}$ is equivalent to $\mathrm{I} \mathrm{cm}$ in $6 \mathrm{~min}$, or $10 \mathrm{~cm} / \mathrm{hr}$. This agrees with the results of the invasion test (Harvey, 1954), where it was found that sperms would pass through $3 \mathrm{~cm}$ of good mucus in $15 \mathrm{~min}$. The sperms with maximum speed are moving about twice as rapidly as this and we may safely assume that freshly ejaculated sperms in mucus in situ are even faster, so that it would be quite possible for sperms, by their own progressive movement, to reach the oviduct in $30 \mathrm{~min}$ after insemination, as reported by Rubenstein, Strauss, Lazaras \& Hawkin (I95I). This does not, of course, prove that sperm motility is the only, or even the most important, factor concerned in the transport of spermatozoa through the genital tract.

\section{ACKNOWLEDGMENT}

This work was supported by a grant from the South-West Regional Hospital Board.

\section{REFERENCES}

Baker, F. N., Gragle, R. G., Salisbury, G. W. \& VanDemark, N. L. (I957) Spermatozoan velocities in vitro: a simple method of measurement. Fertility $\&$ Sterility, 8, 149.

Dотт, H. M. \& Walton, A. (1953) Apparatus for studying semen metabolism and sperm motility. 7. Physiol. 122, I $P$.

Emmens, C. W. (I947) The motility and viability of rabbit spermatozoa at different hydrogen-ion concentrations. F. Physiol. 106, $47 \mathrm{I}$.

Harvey, C. (1953) A fertility index derived from semen analysis. 7. clin. Path. 6, 232.

Harvey, C. (1954) An experimental study of the penetration of human cervical mucus by spermatozoa in vitro. 7. Obstet. Gynaec., Brit. Emp. 61, 480 .

Harvey, C. \& JAckson, M. H. (I945) Assessment of male fertility by semen analysis. Lancet, ii, 99, 134 .

MacLeod, J. ( I95I) Semen quality in one thousand men of known fertility and in eight hundred cases of infertile marriage. Fertility $\mathcal{E}$ Sterility, 2, I I 5 .

MacLeOD, J. \& FReund, M. (1958) The carbohydrate metabolism of human spermatozoa in seminal plasma. Studies on Fertility, ro, 52.

ManN, T. (I958) Biochemical basis of spermicidal activity. Studies on Fertility, 9, 3.

Rothschild, LoRd (I953) A new method of measuring sperm speeds. Nature, Lond. I7I, 512.

Rozin, S. (1958) The role of seminal plasma in motility of spermatozoa. Acta med. or., Jerusalem, 17, 24.

Rubenstein, B. B., Strauss, H., Lazarus, M. L. \& Hawkin, H. (i95 I) Sperm survival in women. Fertility \& Sterility, 2, I5.

Siegel, S. (1956) Non-parametric statistics, p. I 16. McGraw Hill, New York. 